\title{
Popular Contraceptive Methods in Women Aged 35 Years and Older Attending Health Centers of 4 Cities in Khuzestan Province, Iran
}

\author{
Sedighe Nouhjah ${ }^{1,{ }^{*}}$, Elham Amiri ${ }^{1}$, Azim Khodai $^{1}$, Azar Yazdanpanah ${ }^{1}$, Maryam Nadi Baghu ${ }^{1}$ \\ ${ }^{1}$ Health Research Institute, Diabetes Research Center, Ahvaz Jundishapur University of Medical Sciences, Ahvaz, IR Iran \\ *Corresponding author: Sedighe Nouhjah, Health research Institute,Diabetes research center, Ahvaz Jundishapur University of Medical Sciences, Ahvaz, IR Iran. Tel: +98-6113914501, \\ E-mail:s_nouhjah@yahoo.com
}

Received: February 08, 2012; Revised: Jun 18, 2012; Accepted: July 29, 2013

\begin{abstract}
Background: The prevalence of unintended pregnancy and associated risks are higher in late reproductive years. Limited studies have focused on contraceptive choices in these women. The aim of the study was to identify contraceptive choices and their related factors in women 35 years or older attending health centers of Khuzestan province.

Objectives: Additionally, several line of evidence indicated relationship between increasing maternal age and poor pregnancy outcomes $(1,2)$. Pregnancies above the age of 35 are accompanied with more risks for complication related to pregnancy as compared to younger women (3-5). Risk of spontaneous abortion is $74.4 \%$ in mothers aged 45 years or more.

Patients and Methods: In a cross-sectional study 1584 women aged 35 years and older attending public health centers of four cities of Khuzestan were studied. We used an interviewer-administered questionnaire for data collection. Women investigators were recruited for interview and filling the questionnaire. Participants were assured of the confidentiality of their responses.

Results: The mean age of women was $39.8 \pm 4.2$ years. The most popular contraceptive methods used in this age group were oral contraceptive pills (31.4\%), condom (28.1\%), and tubal ligation (14.8\%). Less effective contraceptive methods were used in $41.5 \%$ of women. Significant associations were found between the use of effective methods and literacy of husband ( $\mathrm{OR}=0.80,95 \% \mathrm{CI}: 0.75,0.91)$, city of residence $(\mathrm{OR}=0,92,95 \% \mathrm{CI}: 0.87$ - 0.97), women age $(\mathrm{OR}=0.97,95 \% \mathrm{CI}$; 0.94 - 0.99), and women education $(\mathrm{OR}=0.87,95 \% \mathrm{CI}: 0.76$ - 0.99$)(\mathrm{P}$ $<0.01$ ).

Conclusions: In spite of risk of pregnancy and unintended pregnancy in this age group, about a half of them used less effective contraceptive methods, hence family planning education, and counseling to older women should be a priority in health centers.
\end{abstract}

Keywords: Contraception; Community Health Center; Pregnancy unplanned

\section{Background}

Unintended pregnancy is a widespread global health problem. Although fecundity is reduced in late years of reproduction, rate of unintended pregnancy among women aged 35 and older still remained high (3). More than thirty percent of pregnancies in women older or equal to 35 years are unintended (6). About $51 \%$ of all pregnancies in women aged 40 and older are unintended, and in this age group more than other age groups, about $65 \%$ of unintended pregnancy end to abortion (7). One of the highest ratio of induced abortion is reported in women aged 40 years and older $(3,8,9)$. Unintended pregnancy in older women is associated with higher risks. In women aged 35 - 39 years pregnancy-related mortality ratio is twice in comparison to women aged 25 - 29 years, and women aged 40 and older have a five times greater ratio (6). Maternal mortality is reported 4 times more in mothers aged 35 years and older. Spontaneous abortion rate increases to $26 \%$ in mothers aged 40 - 49 years old (10).

\section{Objectives}

Additionally, several line of evidence indicated an association between increasing maternal age and poor pregnancy outcomes $(1,2)$. Pregnancy above the age of 35 is accompanied with more risks for complications related to pregnancy as compared to younger women (3 - 5). Risk of spontaneous abortion is $74.4 \%$ in mothers aged 45 years and more (11). Older age of mother in pregnancy is associated with an increased risk of prenatal mortality, risk of chromosomal abnormalities, and still birth $(3,10)$. Use of Contraceptive method decreases the proportion of unintended pregnancy and associated risks. Women older than 35 years are more likely to forget contraception use than women aged $20-24$. Although sterilization is still the most popular chosen contraception for women older 35 , in recent years using hormonal methods or withdrawal and rhythm methods is increasing in this age group. No contraception use is reported by about $20 \%$ of women aged $40-44$ and $15 \%$ of women aged $35-39(3,6)$.

Implication for health policy/practice/research/medical education:

Results of this manuscript can be used for family planning program in health center

Copyright (c) 2013, Iranian Red Crescent Medical Journal; Licensee Kowsar Corp. This is an Open Access article distributed under the terms of the Creative Commons Attribution License (http://creativecommons.org/licenses/by/3.0), which permits unrestricted use, distribution, and reproduction in any medium, provided the original work is properly cited. 
Contraceptive choices among younger women have investigated in many previous studies, but studies on the pattern of contraception in late years of reproduction are limited.

Therefore using an effective contraceptive method is very important in this group. The overall aim of this study was to assess contraceptive choices and related factors in women aged 35 and older attending health centers of south western of Iran.

\section{Patients and Methods}

In a descriptive- analytic study 1584 married women aged 35 - 50 years attending public health centers of four cities of Khuzestan province (south western of Iran) were studied.

Four large cities of Khuzestan, Ahvaz, Dezful, Khoramshahr, and Izeh were selected due to having a wider representation of the province.

The populations of these cities are about one million, 400000,150000 and 170000 respectively. The study was performed between October 2009 and December 2010. Every woman aged equal or greater than 35 years seeking family health services (routine care for their children, contraception) during the study period was asked to participate in the study. The sample size was calculated based on a pilot study performed in Ahvaz city (11).

We used an interviewer-administered questionnaire for data collection. Women investigators were recruited for interviewing and filling the questionnaire. Bachelors of public health were recruited as research assistants. Participants were assured of the confidentiality of their responses. We entered and analyzed data through SPSS (version 11.5) software. Chi square and logistic regression tests were performed. The dependent variables were dichotomized (use or nonuse of effective methods) for logistic regression analyses. The level of significance was set at 0.05 .

\section{Results}

384 women from Ahvaz city, 700 from Dezful, 200 from Khoramshahr, and 300 from Izeh city completed the study. The mean age of women was $39.8 \pm 4.2$ years. $26.3 \%$ had experienced 1 - 3 pregnancies and $24.1 \%$ of them experienced 5 or more pregnancies in their reproductive ages.

Experience of at least one abortion was reported in 19.7\% of women. Three most popular methods used in this age group were oral contraceptive pills (31.4\%), condom (28.1\%), and tubal ligation (14.8\%). Less effective contraceptive methods (natural, rhythm and condom) were used in $41.5 \%$ of women. Vasectomy in $1.6 \%$ of participants was chosen as the contraceptive method. Highly educated women were less likely to use effective methods (37.9\% vs. $77.5 \%$ in illiterate women $)(\mathrm{P}<0.001)$. Higher use of more effective methods (hormonal, IUD, and surgical) was reported in women with marriage younger than 18 years (69.7\%), and parity equal or more than 6 (79.5\%) (Table 1$)$.

\begin{tabular}{ccl}
\hline Table 1. Reproductive Characteristic of Participants & \\
\hline Variable & Number & Percent \\
\hline Gravid & 108 & 6.9 \\
\hline 1 & 401 & 25.3 \\
\hline 2 & 416 & 26.3 \\
\hline 3 & 278 & 17.6 \\
\hline 4 & 174 & 11.0 \\
\hline 5 & 207 & 13.1 \\
\hline$\geq 6$ & 1584 & 100 \\
\hline Total & & \\
\hline Parity & 126 & 8.0 \\
\hline 1 & 470 & 29.7 \\
\hline 2 & 422 & 26.7 \\
\hline 3 & 266 & 16.8 \\
\hline 4 & 147 & 9.3 \\
\hline 5 & 151 & 9.5 \\
\hline$\geq 6$ & 1582 & 100 \\
\hline Total & & 19.7 \\
\hline History of Abortion & 312 & 80.3 \\
\hline Yes & 1272 & 100 \\
\hline No & 1584 & \\
\hline Total & & \\
\hline
\end{tabular}


Nouhjah S et al.

Binary logistic regression showed significant associations between using effective contraceptive methods and educational level of women and their husbands, city of residence, and women age (Table 2 , Table 3 , Table 4 ).

Table 2. Contraceptive Methods in Women Aged 35 and Older Attending Health Centers of Four Cities in Khuzestan Province

\begin{tabular}{lll}
\hline Contraceptive Method & Number & Percent \\
\hline Natural & 208 & 13.2 \\
\hline Condom & 445 & 28.2 \\
\hline LD & 444 & 28.1 \\
\hline Mini Pill & 18 & 1.1 \\
\hline Tri Phasic & 37 & 2.3 \\
\hline IUD & 130 & 8.2 \\
\hline Injection & 36 & 2.3 \\
\hline TL & 235 & 14.9 \\
\hline Vasectomy & 25 & 1.6 \\
\hline Rhythm & 3 & 0.2 \\
\hline Total & 1581 & 100 \\
\hline
\end{tabular}

Table 3. Use of Effective Contraceptive Methods (Hormonal, IUD, Surgical) and Less Effective Methods (Natural, Rhythm and Condom) Based on Women Characteristics

\begin{tabular}{|c|c|c|c|}
\hline Variable & $\begin{array}{l}\text { Effective Contraceptive } \\
\text { Methods No., (\%) }\end{array}$ & Less Effective Contraceptive Methods No., (\%) & Significance Level \\
\hline Age, y & & & $<0.001$ \\
\hline $35-39$ & $503(55.8)$ & $398(44.2)$ & \\
\hline $40-57$ & $414(62.2)$ & $252(37.8)$ & \\
\hline Marriage age & & & $<0.001$ \\
\hline$\leq 18$ & $315(69.7)$ & $137(30.3)$ & \\
\hline $18-24$ & $440(57.4)$ & $327(42.6)$ & \\
\hline $25-29$ & $129(46.7)$ & $147(53.3)$ & \\
\hline$\geq 30$ & $39(47.6)$ & $43(52.4)$ & \\
\hline Educational Level of Women & & & $<0.001$ \\
\hline Illiterate & $141(77.5)$ & $41(22.5)$ & \\
\hline Primary & $215(70.0)$ & $92(30.0)$ & \\
\hline Intermediate & $229(64.7)$ & $125(35.3)$ & \\
\hline High School & $232(51.0)$ & $223(49.0)$ & \\
\hline College & $106(37.9)$ & $174(62.1)$ & \\
\hline Literacy of Husband & & & $<0.001$ \\
\hline Illiterate & $95(77.2)$ & $28(22.8)$ & \\
\hline Primary & $174(69.0)$ & $78(31.0)$ & \\
\hline Intermediate & $237(67.5)$ & $114(32.5)$ & \\
\hline High School & $289(57.3)$ & $215(42.7)$ & \\
\hline Collage & $130(37.1)$ & $220(62.9)$ & \\
\hline City of Residence & & & $<0.001$ \\
\hline Dezful & $382(54.8)$ & $315(45.2)$ & \\
\hline Khoramshahr & $129(64.5)$ & $71(35.2)$ & \\
\hline Izeh & $208(69.3)$ & $92(30.7)$ & \\
\hline Ahwaz & $206(53.6)$ & $178(46.4)$ & \\
\hline
\end{tabular}


Nouhjah S et al.

\begin{tabular}{|c|c|c|c|}
\hline Gravidity & & & $<0.001$ \\
\hline 1 & $35(32.7)$ & $72(67.3)$ & \\
\hline 2 & $184(45.9)$ & $217(54.1)$ & \\
\hline 3 & $229(54.6)$ & $188(54.4)$ & \\
\hline 4 & $186(66.9)$ & $92(33.1)$ & \\
\hline 5 & $131(75.3)$ & $43(24.7)$ & \\
\hline$\geq 6$ & $163(78.7)$ & $44(21.3)$ & \\
\hline Parity & & & $<0.001$ \\
\hline 1 & $47(37.6)$ & $78(62.4)$ & \\
\hline 2 & $211(450)$ & $258(55.0)$ & \\
\hline 3 & $239(56.8)$ & $182(43.2)$ & \\
\hline 4 & $191(71.8)$ & $75(28.2)$ & \\
\hline 5 & $117(79.6)$ & $30(20.4)$ & \\
\hline$\geq 6$ & $120(79.5)$ & $31(20.5)$ & \\
\hline History of Abortion & & & NS \\
\hline Yes & $188(60.5)$ & $123(32.5)$ & \\
\hline No & $737(58.0)$ & $533(42.0)$ & \\
\hline
\end{tabular}

Table 4. Results of Regression Logistic 95\% Confidence Interval

\begin{tabular}{llll}
\hline Variable & Odds Ratio & CI & Signification Level \\
\hline Women Education & 0.87 & $0.76-0.99$ & 0.04 \\
\hline Husband's Literacy & 0.82 & $0.72-0.94$ & 0.004 \\
\hline City of Residence & 0.92 & $0.87-0.97$ & 0.007 \\
Gravid a & 1.27 & $0.92-1.7$ & NS \\
Parity & 1.17 & $0.85-1.6$ & NS \\
Women's Age & 0.97 & $0.94-0.99$ & 0.03
\end{tabular}

\section{Discussion}

In spite of a decline in fecundity in late years of reproduction, the prevalence of unintended pregnancy and related complication in pregnancy in this age group is high. In the present study 3 most popular contraceptive methods used by women aged 35 years and older were OCP (31.5\%), condom (28.1\%), and tubal ligation (14.9\%). Similar to our results Musharrafi and colleagues (2003) reported OCP as the most popular method in this age group (30\%) (12). In many prior studies surgical methods were reported as the most popular contraceptive methods in this age group of women in developed countries (13). Because many clients did not return to health centers after referring for surgical methods, our estimation about these methods may be underestimated. In contrast to our finding, Abma et al. reported that only $11 \%$ of women aged $35-39$ years and $6 \%$ of women aged $40-44$ years used old combination of OCP. They reported that concerns about safety of OCP in these age groups lead to low use of this method (14). Less effective methods (natural, rhythm and condom) were used in $41.5 \%$ of participants.
Frost and Darroch reported that women aged 35-44 years were more likely to use natural, condom, and other barrier methods (15). Studies indicated that in spite of choosing sterilization as a common contraceptive method, hormonal methods or withdrawal and rhythm were chosen by women aged 35 years and older in recent years (16, 17). Our study had some limitations. Populations of the study were women attending health centers and may be not an actual representation of women in this age group. We estimated most popular methods used by women in this study, but we missed women who did not use any methods in this age group. Recent studies reported higher rate of contraceptive nonuse in this age group $(3,17$, 18). A relative big sample size, and focus on this specific age group were the strengths of this study.

In spite of risk of pregnancy and unintended pregnancy in this age group, about a half of them used less effective contraceptive methods. Health centers should take extra care to counsel women of this age group. Counseling about hazards of pregnancy in these years and also non contraceptive benefits of hormonal methods should be a priority in health centers. 


\section{Acknowledgements}

We would like to thank the students of public health for their cooperation in this study and women attending health centers for their participation in the project.

\section{Authors Contributions}

Sedighe Nouhjah contributed to study designing, data analyzing, and paper writing, Maryam Nadi Baghu, Elhami Amiri, Azim Khodai, and Azar Yazdanpanah contributed to study data collection and paper writing.

\section{Financial Disclosure}

None declared.

\section{Funding/Support}

This study was supported by a grant from Jundishapur University of Medical Sciences of Ahvaz.

\section{References}

1. Bianco A, Stone J, Lynch L, Lapinski R, Berkowitz G, Berkowitz RL. Pregnancy outcome at age 40 and older. Obstet Gynecol. 1996;87(6):917-22.

2. Fretts RC, Schmittdiel J, McLean FH, Usher RH, Goldman MB. Increased maternal age and the risk of fetal death. $N$ Engl J Med. 1995;333(15):953-7.

3. Brunner Huber LR, Huber KR. Contraceptive choices of women 35-44 years of age: findings from the behavioral risk factor surveillance system. Ann Epidemiol. 2009;19(11):823-33.

4. Viegas OA, Leong WP, Ahmed S, Ratnam SS. Obstetrical outcome with increasing maternal age. J Biosoc Sci.1994;26(2):261-7.

5. Callaghan WM, Berg CJ. Pregnancy-related mortality among women aged 35 years and older, United States, 1991-1997. Obstet
Gynecol. 2003;102(5 Pt 1):1015-21.

6. Godfrey EM, Chin NP, Fielding SL, Fiscella K, Dozier A. Contraceptive methods and use by women aged 35 and over: A qualitative study of perspectives. BMC Womens Health. 2011;11:5.

7. Henshaw SK. Unintended pregnancy in the United States. Fam Plann Perspect.1998;30(1):24-29.

8. Gamble SB, Strauss LT, Parker WY, Cook DA, Zane SB, Hamdan S. Abortion surveillance--United States, 2005. MMWR Surveill Summ. 2008;57(13):1-32.

9. Jones RK, Darroch JE, Henshaw SK. Patterns in the socioeconomic characteristics of women obtaining abortions in 2000-2001. Perspect Sex Reprod Health. 2002;34(5):226-35.

10. Carr BR, DelConte A. Using a low-dose contraceptive in women 35 years of age and over: 20 microg estradiol/100 microg levonorgestrel. Contraception. 2002;65(6):397-402.

11. NadiBaghoo M, Nouhjah S, Haghighizadeh MH. The pattern of using family planning methods in women over 35 years old referred to Ahvaz health centers in 2010. Jentashapir 2012. 2013;2(4):175-81.

12. Moshrefi M, Rahimi Kian F, Mehran A, Gheitoli H. The rate of using different contraception methods among women attending to Tehran south health centers; Iran. Payesh Health. 2005;4(1).

13. Mosher WD, Martinez GM, Chandra A, Abma JC, Willson SJ. Use of contraception and use of family planning services in the United States: 1982-2002. Adv Data. 2004(350):1-36.

14. Abma JC, Chandra A, Mosher WD, Peterson LS, Piccinino LJ. Fertility, family planning, and women's health: new data from the 1995 National Survey of Family Growth. Vital Health Stat 23. 1997(19):1114.

15. Frost JJ, Darroch JE. Factors associated with contraceptive choice and inconsistent method use, United States, 2004. Perspect Sex Reprod Health. 2008;40(2):94-104.

16. Sahin NH, Kharbouch SB. Perimenopausal contraception in Turkish women: A cross-sectional study. BMC Nurs. 2007;6:1.

17. Frost JJ, Singh S, Finer LB. Factors associated with contraceptive use and nonuse, United States, 2004. Perspect Sex Reprod Health. 2007;39(2):90-9.

18. Wu J, Meldrum S, Dozier A, Stanwood N, Fiscella K. Contraceptive nonuse among US women at risk for unplanned pregnancy. Contraception. 2008;78(4):284-9. 